\title{
Price Elasticity of Demand and Capacity-Restraint Transit Fare Strategy: A Case Study of Bangkok Mass Transit System
}

\author{
Ackchai Sirikijpanichkul $^{1}$ and Sarintorn Winyoopadit ${ }^{2}$ \\ ${ }^{1}$ Lecturer, Faculty of Engineering, Kasetsart University, 50 Ngam Wong Wan Road, Ladyaow, Chatuchak, Bangkok, \\ Thailand, 10900. E-mail: fengacs@ ku.ac.th (corresponding author). \\ ${ }^{2}$ Public Sector Development Officer, Office of the Public Sector Development Commission Thailand (OPDC), 59/1 \\ Pitsanulok Road, Dusit, Bangkok, Thailand, 10300. E-mail: sarintornw@gmail.com
}

Engineering Management

Received February 2, 2014; received revision March 31, 2014; accepted April 8, 2014

Available online May 22, 2014

\begin{abstract}
Traffic congestion is a chronic problem of Bangkok. Similar to other metropolises, the city perpetually seeks for alternatives to road travel. Mass rapid transit seems to be the only way out that is expected to mitigate traffic congestion in the city. However, without common fare system, travelers need to pay an initial entrance fee every time they enter each transit system. This excess cost tapers the demand and affects the efficient use of the system. This research investigates the influence of fare price on transit use which is measured by price elasticity of demand and proposes the optimum fare price if the common fare is used. The analysis is based on the findings from the stated preference survey techniques. Finally, the conclusion on fare level that encourage more patronage, maintain service quality and operator revenue is addressed.
\end{abstract}

Keywords: Price elasticity of demand, capacity-restraint, transit fare strategy.

\section{Introduction}

Having realized that road transport will no longer move people and freight efficiently and sustainably in the future, Thailand has come up with a major investment plan to transform itself into a more transit-oriented country. The national roadmap called "Thailand 2020" will involve a massive investment in transportation infrastructure development that is expected to foster Thailand as a strategic hub of ASEAN. According to the plan, approximately 80 percent of the unprecedented 2.2 trillion Baht loan will be spent on upgrading the existing, and establishing a new rail infrastructure network including track doubling, extension of new railway line, completing Bangkok metro line network, and establishing a new High-speed rail network.

Traveling by rail is superior to road by the fact that the transit unit is operated on an exclusive right of way therefore the travel time is predictable and reliable. However, such characteristics limit the access to the system and make rail travel less attractive in the sense that rail passengers need to make several transfers before getting into a station instead of enjoying a door-to-door service as motorists do. Apart from such inconvenience, each transfer affects passenger travel time and cost. Although some measures are proposed to facilitate smooth transfers at intermodal or transfer stations such as installation of Intermodal Transfer Facilities (ITF) or the upgrade of station vicinity to meet Transit Oriented Design (TOD) concept, some passengers still feel uncomfortable to use rail transit as they need to pay an initial entrance fee every time they transfer to another transit system especially those who travel in group or make a very short-distance trip.

Common ticketing system comes in place to solve this problem as it allows travelers to transfer as often as they can via one common ticket and one common rebated entrance fee. Then the fare will be calculated based on distance travelled or number of zones crossed regardless of how many transfers are made during the course of the journey. The implementation of common ticketing system in Bangkok is under process and expected to be alive in the next five years. Before that happens, it is necessary to understand how the new fare structure will change the way people travel by investigating how transit demand change in accordance with the change in transit fare which can be explained by the economic measures called price elasticity of demand. In this study, the measures are determined based on the result of field survey data using stated preference techniques. Finally, the conclusions on new fare levels that promote transit patronage, maintain service quality and sustain operator revenue are addressed.

\section{Overview of Bangkok Mass Transit Network}


The existing mass transit network in Bangkok is composed of four distinguishing systems including Bangkok Mass Transit System (BTS Skytrain) and Bangkok Bus Rapid Transit (Bangkok BRT) operated by Bangkok Mass Transit System Public Company Limited (BTSC) under a concession granted by the Bangkok Metropolitan Administration (BMA), Metropolitan Rapid Transit (MRT Underground Train) operated by the Bangkok Metro Public Company Limited (BMCL) under a concession granted by the Mass Rapid Transit Authority of Thailand (MRTA), and Suvarnabhumi Airport Rail Link (SARL) operated by the State Railway of Thailand as shown in Fig. 1.

The current fare strategies of all mass transit lines are typically distance-based where every passenger needs to pay an initial entrance fee every time they enter a transit system or transfer to another transit system then the fare level varies afterwards subject to the distance traveled. The fare structure of a single journey for each transit system in Bangkok is shown in Fig 2.

In the year 2020, Thai government aims at completing the whole mass transit network in Bangkok which includes 10 lines illustrated in Fig 3.

The key concern raised as a research problem is, without an integrated fare structure, passengers are likely to pay an extremely high cumulative fare especially those who live in the remote areas and inevitably forced to make several transfers before reaching their destination. In such cases, the government effort to shift travel demand from road to rail may not be satisfactorily achieved. The next session explains how transit fare affects passenger demand and also the influencing factors that affect passenger perception on transit fare.

\section{Influence of Transit Fare on Passenger Demand}

\subsection{Price and Demand}

Basically, when the price of any goods or service is increased, people tend to buy lower amount of such goods or service, and vice versa, when the price of goods or service is scaled down, people tend to buy more amount of such goods or service, This common behavior is explained by "the economics law of demand" (Marshall, 1920). Public transit demand behaviors also obey the same law as depicted in Fig. 4A. Nevertheless, different groups of people may have different willingness to pay for the same transport service subject to their preference on the service as illustrated by the shift in demand shown in Fig. 4B. Litman (2004) reviewed the influencing factors that affect passengers' preference on public transit service and concluded that demographics, commercial activities, transport options, land use, demand management, and prices were the primary factors. Among all, prices are the direct, perceived costs of using a service. Transport price normally reflects both direct (out-of-pocket) and indirect travel costs including travel time, discomfort and risk.

\subsection{Price Elasticity of Demand}

The degree of changes in demand subject to change in service characteristics is measured by an elasticity of demand. If all the influencing factors are controlled except price, the degree of change in demand, $\Delta \mathrm{D} / \mathrm{D}$ subject to change in price, $\Delta \mathrm{P} / \mathrm{P})$ is called a price elasticity of demand $\left(E_{d}\right)$ as defined by Eq. (1) (Parkin et al., 2002).

$$
E_{d}=\frac{\left(\frac{\Delta D}{D}\right)}{\left(\frac{\Delta P}{P}\right)}
$$

Each range of the price elasticity of demand $\left(E_{d}\right)$ can be interpreted as shown in Table 1.

Litman (2012) found that changes in transit fare can affect passengers on their trip frequency, route, mode, destination, scheduling, vehicle type, parking location, type of services selected and location decisions.

The price elasticity of demand $\left(E_{d}\right)$ is a useful indicator of how individuals react to the change of transit fare and assist decision makers to design optimal transit fare structure that accommodates the needs of individual transit user group. Such optimal fare structure will not only satisfy transit users' willing-to-pay but also allow transit operators to keep the level of transit demand under control while sustaining overall level of income.

The changes in transit fare will affect operators' revenue formulated in Eq. (2), where Revenue (R) is a multiplication of Price (P) and Demand (D), according to the relationships shown in Table 2 .

$$
R=P \times D
$$

\subsection{Influencing Factors on Price Elasticity of Demand}

According to the literature review by Litman (2004), McCollom and Pratt (2004), TRL (2004), Paulley et al. (2006), Taylor et al. (2009), Wang (2011), Wardman and Shires (2003 and 2011), the price elasticity of transit demand is influenced by the following factors:

- User characteristics: High earners tend to be less price-sensitive but more quality- sensitive in comparison to low earners.

- Trip characteristics: Non-commuting trips (for recreational purposes) tend to be more price-sensitive than commuting trips (for business and educational purposes).

- Mode and route: Captive riders tend to be less pricesensitive than choice riders.

- Geography: People living in the large congested city tend to be less price-sensitive than those living in the smaller city.

- Type and direction of price change: Elasticity tends to be higher for high fare levels. Fare increase tends to cause greater impact on passenger reduction than the same level of fare reduction to increase ridership.

- Time Period: Elasticity increases over time as passengers take price changes into their decisions on where to live or work.

\subsection{Transit Fare Policy}

\subsubsection{Objectives}

Transit fare policy is specified to fulfill some key objectives including maximization of service patronage, profits, and equity to all target groups including elderly, students, handicaps and workforce. 


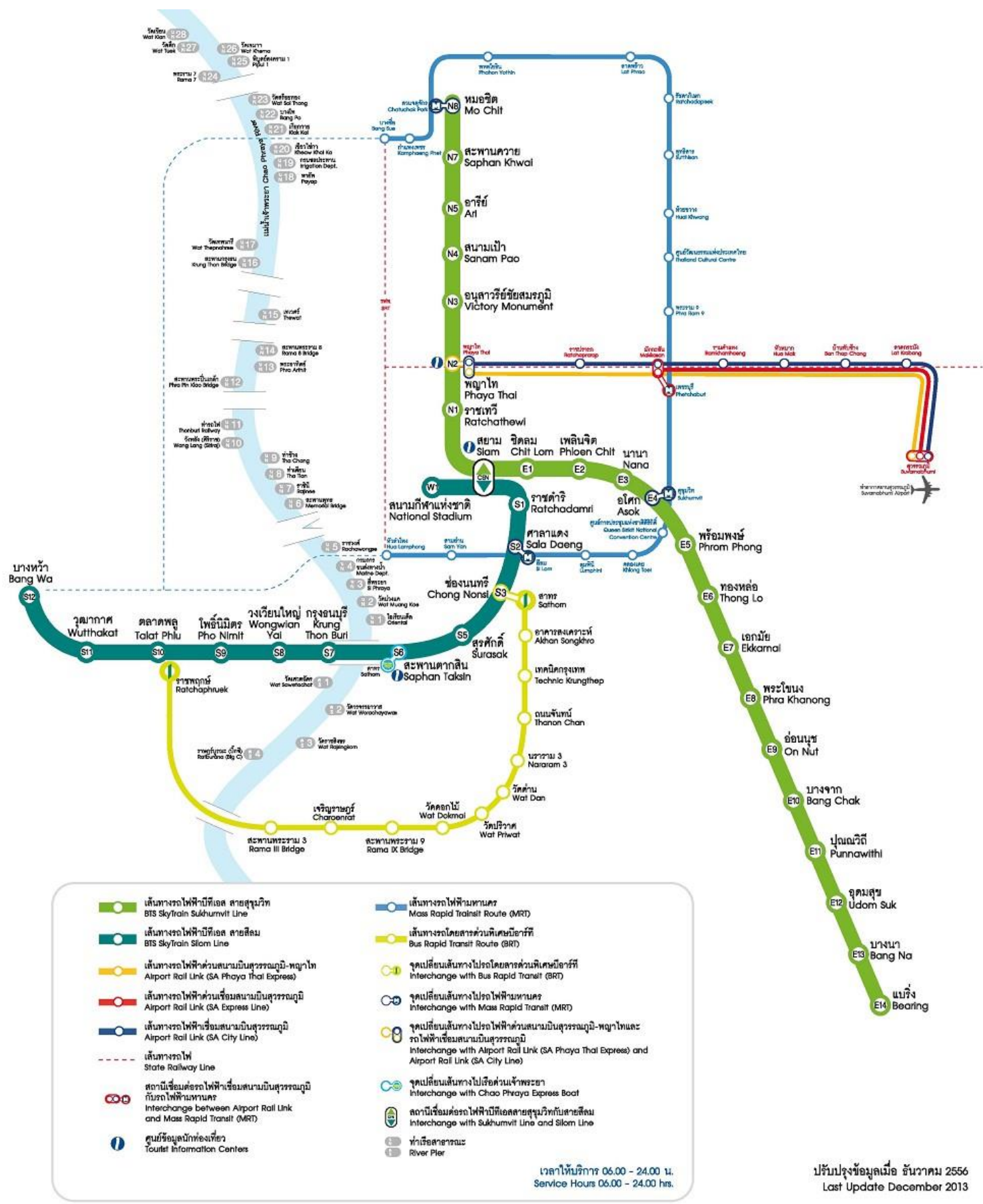

Fig. 1. The existing mass transit network in Bangkok (Source: Bangkok Mass Transit System PCL, reprinted with permission)

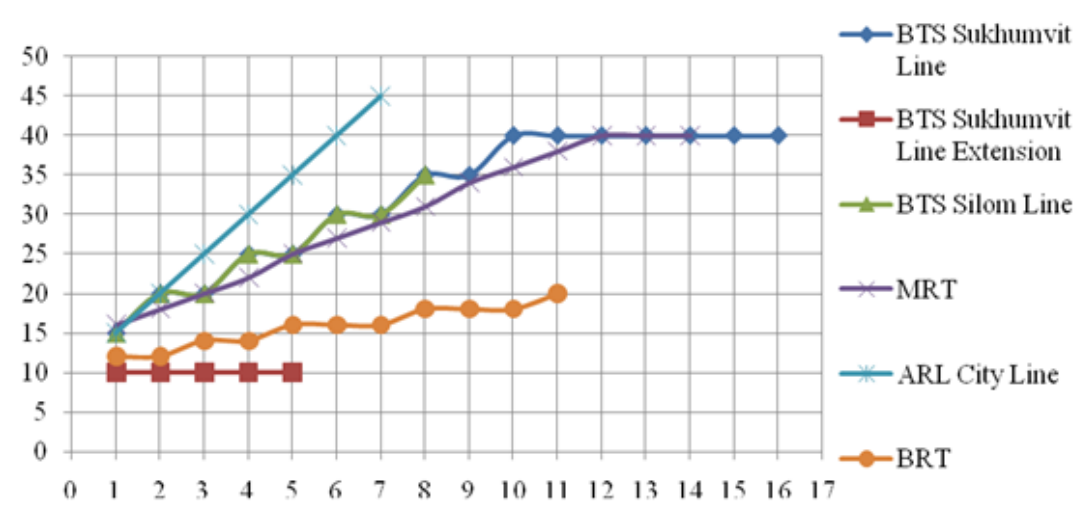

Fig. 2. The current fare structure of a single journey for each transit system in Bangkok 
16 Sirikijpanichkul, A. and Winyoopadit, S.

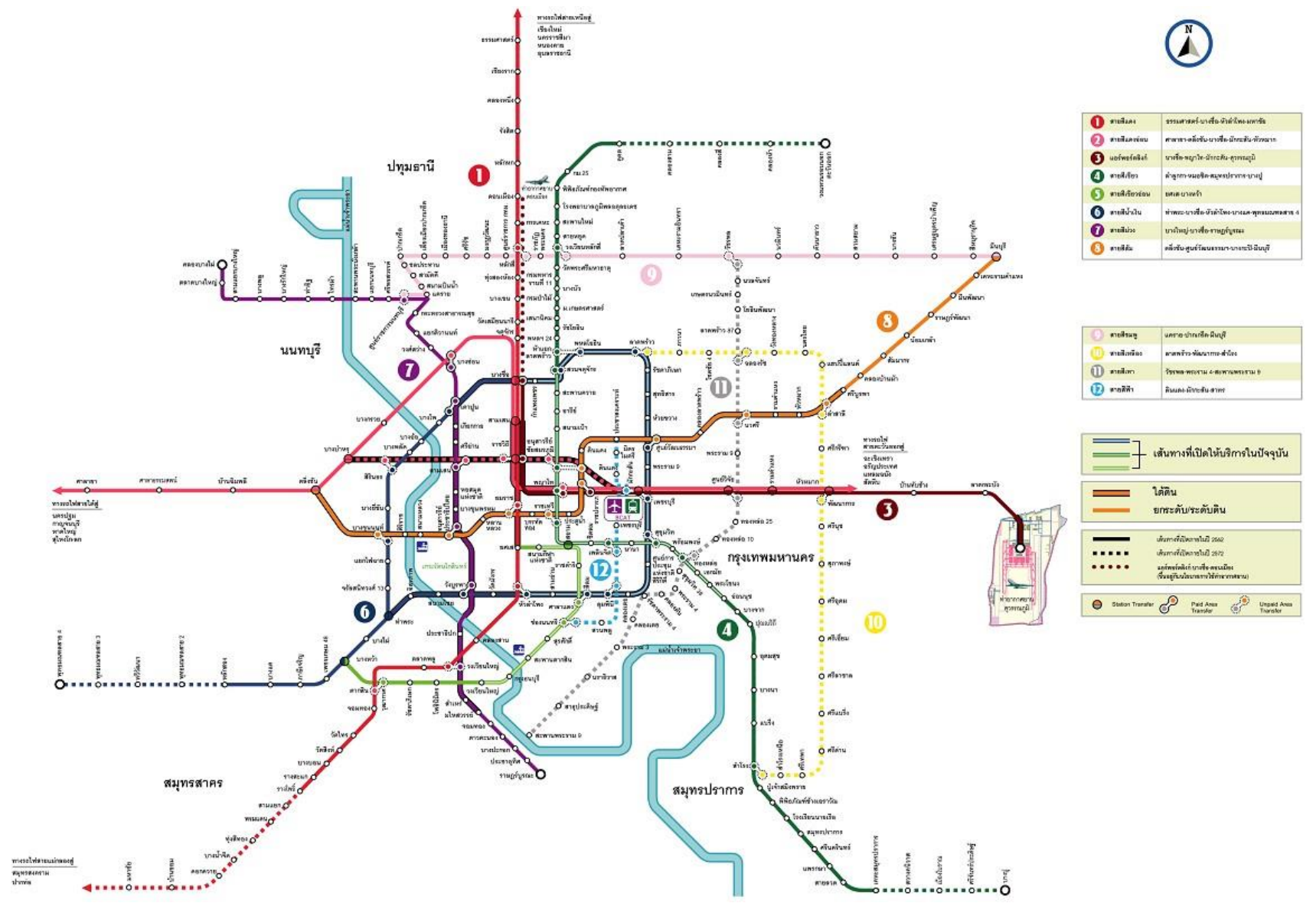

Fig 3. The complete mass transit network in Bangkok 2020 perspective

(Source: Office of Transport and Traffic Policy and Planning, Ministry of Transport, reprinted with permission)

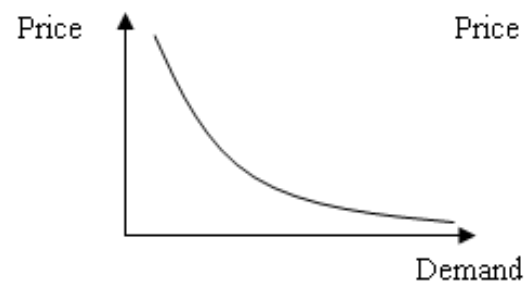

A

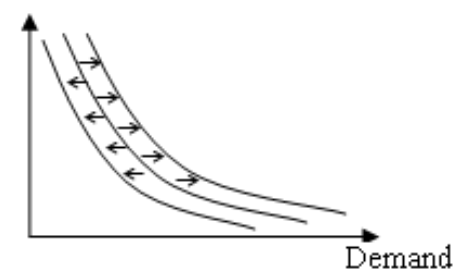

B

$\begin{array}{lll}\text { A) Market demand curve } & \text { B) Shift in market demand }\end{array}$

Fig. 4. Demand curve

Table 1. Interpretation of price elasticity of demand $\left(E_{d}\right)$

\begin{tabular}{|c|c|c|}
\hline Range of $E_{d}$ & $\begin{array}{c}\text { Terminology } \\
\text { (Parkin et al. 2002) } \\
\end{array}$ & Interpretation \\
\hline $\mathrm{E}_{\mathrm{d}}=0$ & Perfectly inelastic demand & $\begin{array}{c}\text { No matter how price is changed, there will be no } \\
\text { effect on demand. }\end{array}$ \\
\hline$-1<\mathrm{E}_{\mathrm{d}}<0$ & Inelastic or relatively inelastic demand & $\begin{array}{c}\text { The change in demand is behind the change in } \\
\text { price. }\end{array}$ \\
\hline$E_{d}=-1$ & $\begin{array}{l}\text { Unit elastic, unit elasticity, unitary elasticity, or } \\
\text { unitarily elastic demand }\end{array}$ & $\begin{array}{l}\text { The change in demand affects the change in price } \\
\text { at the same scale. }\end{array}$ \\
\hline$-\infty<\mathrm{E}_{\mathrm{d}}<-1$ & Elastic or relatively elastic demand & $\begin{array}{l}\text { The change in demand advances the change in } \\
\text { price. }\end{array}$ \\
\hline$E_{d}=-\infty$ & Perfectly elastic demand & $\begin{array}{c}\text { Changing of price at marginal scale, affects } \\
\text { demand significantly. }\end{array}$ \\
\hline
\end{tabular}


Table 2. The relationship between the change in transit fare $(\Delta \mathrm{P})$ and the change in operators' revenue $(\Delta \mathrm{R})$

\begin{tabular}{|c|c|c|c|}
\hline \multirow{2}{*}{$\begin{array}{l}\text { Change in transit fare } \\
\qquad(\Delta \mathrm{P})\end{array}$} & \multicolumn{3}{|c|}{ Type of elasticity of demand $\left(\mathrm{E}_{\mathrm{d}}\right)$ / Change in operators' revenue $(\Delta \mathrm{R})$} \\
\hline & Elastic & Unit elastic & Inelastic \\
\hline $\mathrm{P}$ increased $(+\Delta \mathrm{P})$ & Revenue decreased $(-\Delta \mathrm{R})$ & \multirow{2}{*}{ Revenue unchanged } & Revenue increased $(+\Delta R)$ \\
\hline $\mathrm{P}$ decreased $(-\Delta \mathrm{P})$ & Revenue increased $(+\Delta \mathrm{R})$ & & Revenue decreased $(-\Delta R)$ \\
\hline
\end{tabular}

\subsubsection{Constraints}

Nevertheless, some constraints need to be taken into account including the price elasticity of demand, which limits alternatives to fare structure, level of services and fare level of competing modes, equity to all target groups, necessity and affordability of the service, ease and convenience for payment and fare collection, and negotiation amongst conflicting objectives.

\subsubsection{Influencing factors}

Transit fare policy also relies on some influencing factors include government policies, financial management, designed level of service, operating costs, quantity and quality of competing modes, passenger lifestyle.

\subsubsection{Fare structure}

Objectives, constraints and influencing factors are taken into considerations for designing a fare structure which needs to be chosen among the following alternatives: Flat, Zonal, and Graduate of which the definitions, advantages, disadvantages, and examples are summarized as follows.

\subsubsection{Flat fare}

A single fare paid regardless of distance travelled. Its advantages include ease and convenience for payment and fare collection. This fare structure discourages short distance passengers and subsidy may be needed to compensate loss of income from long distance passengers.

\subsubsection{Zonal fare}

The service area is divided into a number of zones. Fares are calculated based on the number of zones boundaries crossed during the trip. A flat faxre applied for travelling within in a designated zone. This fare structure is suitable for large network. But it discourages passengers who need to cross several boundaries and more complicate fare collection system is needed.

\subsubsection{Graduate fare}

A passenger initially pays an entry charge every time they enter a transit system, then an additional incremental fare is calculated based on a "pay as you go" basis. This fare structure is rational and equitable for all passenger groups. But it is more costly for short-distance and intermodal travelers.

\subsubsection{Common or rebated fare}

To overcome the shortcoming of the graduate fare structure that charges additional entry fee for every transfer a passenger makes, a common or rebated fare structure is introduced. Under the common or rebated fare, the passenger only needs to pay a single rebated entry charge regardless of how many transfers he or she makes and pay additional incremental fare based on a "pay as you go" basis considering all the intermediate transit systems between trip origin and destination as a single integrated system. The system requires a common ticketing system which generates an electronic log of every passenger movement to a central clearing house that decides how to rebate the boarding charge to each passenger and divide the fare between system operators rationally.

\subsection{Transit Line Capacity (C)}

To determine the maximum number of passengers a transit line can carry passes a reference point during a specific time period known as transit line capacity (C), the following parameters are required:

\subsubsection{Vehicle capacity $\left(C_{v}\right)$}

The maximum number of spaces provided in a single vehicle for both standing and seating passengers. Spaces for the former passengers are determined by deducting vehicle floor area with seating area and dividing this remaining terms by density of standing passengers as quoted in Eq. (3) and (4),

$$
\begin{gathered}
C_{v}=\left(\frac{A_{\text {seat }}}{a_{\text {seat }}}+\frac{A_{s \tan d}}{a_{\text {stan } d}}\right) \\
A_{v}=A_{\text {seat }}+A_{s \tan d}
\end{gathered}
$$

Where $A_{v} \quad$ Usable vehicle floor area

$A_{\text {seat }}$ Vehicle floor area designaged for passenger seats where each seat occupied area $a_{\text {seat }}$

$\mathrm{A}_{\text {standing }}$ Vehicle floor area designaged for standing passengers where each passenger occupied area $\mathrm{a}_{\text {stand }}$

\subsubsection{Number of vehicles per transit unit $(N)$}

Number of vehicles travelling together in the same compartment called a transit unit.

\subsubsection{Maximum frequency $\left(f_{\max }\right)$ or minimum headway $\left(\mathbf{h}_{\text {min }}\right)$}

Maximum frequency $\left(f_{\max }\right)$ is defined as the maximum number of transit units that pass a referenced point during a specific time period. Invert of maximum frequency $\left(\mathrm{f}_{\max }\right)$ is considered as minimum headway $\left(\mathrm{h}_{\min }\right)$ defined as the minimum lagged time that the successor transit unit will repeat the same referenced point of the former transit unit. The relationship between maximum frequency $\left(f_{\max }\right)$ in transit units/hour and minimum headway $\left(\mathrm{h}_{\min }\right)$ in minutes per transit unit is as Eq. (5),

$$
h_{\min }=\frac{60}{f_{\max }}
$$




\subsubsection{Maximum passenger loading ( $P$ ) and load factor} (a)

Maximum passenger loading $(\mathrm{P})$ is defined as the number of passengers observed on the maximum loading section (MLS) of the line during a specific time period. When ratio between maximum passenger loading $(\mathrm{P})$ and transit line capacity $(\mathrm{C})$ indicates how dense the system is as Eq. (6).

$$
\alpha=\frac{P}{C}
$$

Vuchic (2005) determined the relationship between the above parameters as Eq. (7) and (8),

$$
\begin{gathered}
C=n \times C_{v} \times f_{\max } \\
C=\frac{n \times C_{v} \times 60}{h_{\text {min }}}
\end{gathered}
$$

\section{Research Methodology}

The research methodology comprises of three major steps, including field survey, price elasticity of demand and transit fare strategy, of which the details are described in the following sub sessions.

\subsection{Field Survey}

A field survey is conducted to acquire a primary dataset on how existing transit passengers and potential users respond to the change in fare level which provides the key input into the analysis of price elasticity of demand. The data are collected via an interview with a questionnaire.

\subsubsection{Questionnaire design}

Each questionnaire is designed to reveal the detailed information of the following influencing factors:

- Respondent's characteristics including gender, age, occupation, and monthly income;

- Trip characteristics including trip origin and destination, trip purpose, travel distance, travel time, travel cost, group size, and vehicle occupancy;

- Modes of travel including captive and choice rider, private vehicle only or non-motorized mode only;

- Type of ticket used by transit passengers including Single Journey Ticket (SJT), Stored Value Ticket (SVT), or travel pass;

- Access modes to the transit system including bus, public van, taxi, motorcycle taxi, boat, other transit system;

- Attitudes of users and non-users;

- Sensitivity to changes in transit fare.

\subsubsection{Stated preference interview}

To understand the level of sensitivity to changes in transit fare, it is necessary to simulate a situation where the transit users need to decide "what is the maximum level of fare increase (from the range of hypothetical levels provided) they can tolerate to remain using the transit system ?"; on the other hand, the non-transit users need to decide "what is minimum level of fare decrease (from the range of hypothetical levels provided) they start to shift their current travel modes into transit system ?." This kind of experiment involved stated preference survey technique where an individual interviewee is asked to rank or rate the hypothetical options pre-determined by the interviewer.

According to Yamane (1967), to collect the interview data representing population size of more than 100,000 with the expected 95 percent level of confident, at least 400 interview samples are required. For this research, 2,000 samples of specific target groups mainly include those who have activities inside the coverage area of intermodal transfer facilities are randomly selected and interviewed. The survey was carried out during February 2012 - October 2013. Additional 1,400 samples were collected as an extension of 600 samples collected during the pilot stage carried out by Orachunsuntorn et al (2013).

\subsection{Price Elasticity of Demand}

All the responses from the field survey are filtered, labeled, sorted, and grouped according to the influencing factors as listed in sub-section 4.1.1 using Statistical Package for the Social Sciences (SPSS). For each level of factor, the price elasticity of demand is calculated according to the process shown in Fig. 5.

To determine the price elasticity of demand, each interviewee is also asked how much he or she is spending to travel from his or her origin to destination. How he or she responds to the change of transit fare is investigated by stated preference technique. For example, if the interviewee is currently a transit user and spends 30 Baht on his or her trip, he or she is asked whether he or she will stop using transit system if the fare increases by $5,10,15$, 20 Baht. On the other hand, if the interviewee is not currently a transit user (e.g. bus or car) and spends 20 Baht on his or her trip, he or she is asked whether he or she will shift to a transit system if the current fare decreases by 5 , 10, 15, 20 Baht. Then, the sensitivity to transit fare (percentage of price change) can be determine and sorted ascendingly. At the $85^{\text {th }}$ percentile, it is assumed that majority of interviewee will change their mode and the sensitivity to transit fare at this level is used to determine the price elasticity of demand of each group of influencing factors e.g. age group, distance travelled, income, trip purpose and ticket type.

For example, the $85^{\text {th }}$ percentile of sensitivity to transit fare of home-based work purpose (340 out of 400 samples) is 0.79 . Then, the price elasticity of demand of homebased work purpose is determined as $-0.85 / 0.79=-1.07$. The price elasticity of demand for each group of influencing factors can be determined following the same procedure. 


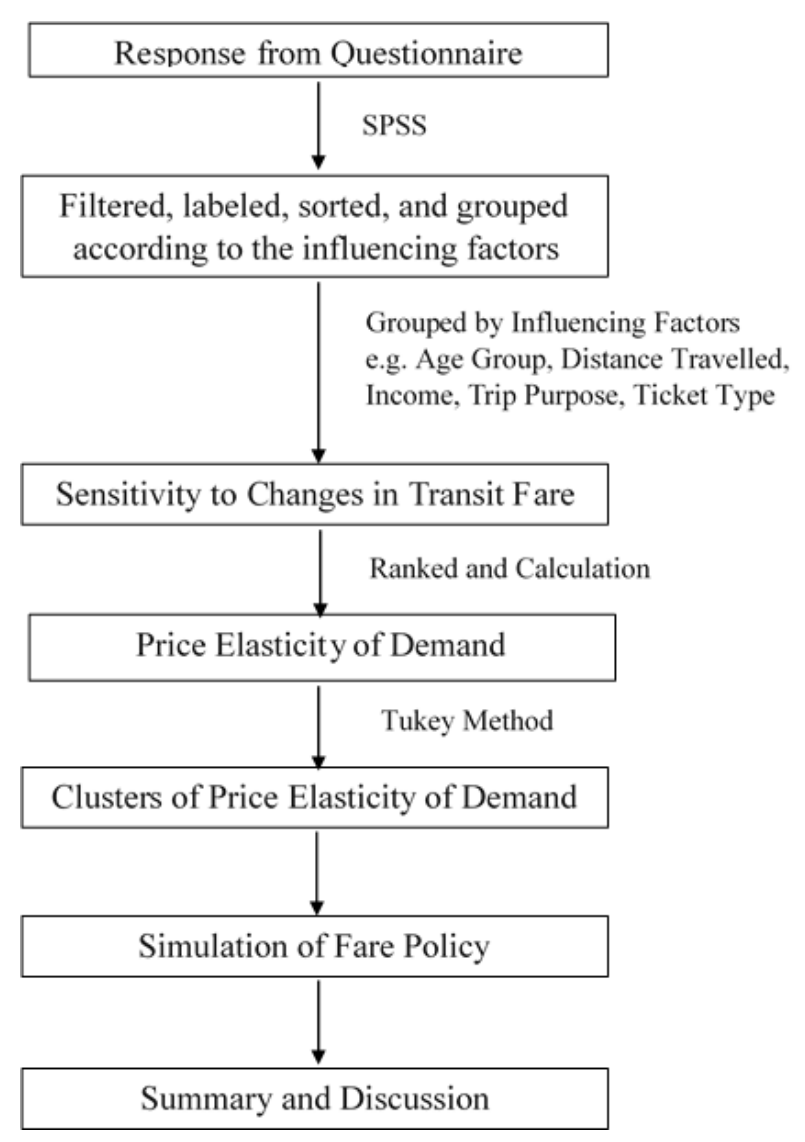

Fig. 5. Determination of price elasticity of demand

\subsubsection{Multiple comparison}

The price elasticity of demand of each factor level is compared under one-way layout experiment to investigate if the changes in factor levels affect the price elasticity of demand so that a rational clustering of the price elastic of demand can be accommodated. The theorem of Welch's $t$ test which is an adaptation of Student's t-test $(\mathrm{Wu}$ and Hamada 2000) as shown in Eq. (9) is applicable for this case, where the sample sizes and variance between factor levels are different.

$$
\left|t_{i j}\right|=\left|\frac{\overline{E_{d j .}}-\overline{E_{d i .}}}{\sqrt{\frac{s_{j}^{2}}{n_{j}}-\frac{s_{i}^{2}}{n_{i}}}}\right|
$$

Where ${\overline{E_{d i}}}_{\overline{E_{d}}}$ is the sample mean of price elasticity of demand with factor levels $i$ and $j$, respectively

$s_{i}^{2}, s_{j}^{2}$ is the sample variance of price elasticity of demand with factor levels $\mathrm{i}$ and $\mathrm{j}$, respectively

$n_{i}, n_{j}$. is the number of samples with factor levels $\mathrm{i}$ and $\mathrm{j}$, respectively

\subsubsection{Clustering}

In this research, the Tukey method is adopted to compare different pairs (and sets) of factor levels simultaneously, when $\bar{E}_{d i} \neq \bar{E}_{d j \text {. }}$ under the studentized range distribution with number of factor levels $\mathrm{k}$ and degree of freedom N-k (Total sample size $\mathrm{N}$ - number of factor levels $\mathrm{k}$ ) at 100 (1- $\alpha$ ) $\%$ confidence interval $q_{k, N-k, \alpha}$ (Wu and Hamada, 2000) as in Eq. (10),

$$
\left|t_{i j}\right|=\left|\frac{\bar{y}_{j .}-\bar{y}_{i .}}{\hat{\sigma} \sqrt{1 / n_{j}+1 / n_{i}}}\right|>\frac{1}{\sqrt{2}} q_{k, N-k, \alpha}
$$

Once the pairs or sets of factor levels with indifferent sample means of price elasticity of demand are proven, they will be clustered into groups that have the same level of sensitivity to change in transit fare.

\subsection{Transit Fare Strategy}

Once the price elasticity of demand for each factor level is identified, the optimal fare and fare structure for each transit network can be discussed and recommended. Constrain of transit network capacity during different scheduling at different time-periods such as peak and offpeak is considered.

\section{Research Outcomes}

\subsection{Attitude toward Mass Transit Use}


The conclusion on attitudes toward mass transit use from the interview survey is shown in Fig. 6. The supportive reasons for mass transit use are avoiding traffic jam (42 $\%$ ), time saving (35\%), and cost saving (23\%); while the contradicting reasons for avoiding mass transit use are poor station access $(30 \%)$, expensive fare $(32 \%)$, and inconvenience especially in intermodal transfers $(38 \%)$.

\subsection{Attitude toward Transit Fare Structure}

When explained and asked which type of fare structure the interviewees preferred, the responses are as shown in Fig. 7. This can be explained that most people using mass transit are commuters who commute from suburb residential areas to the $\mathrm{CBD}$ during the morning peak and return from work back to their places during the evening peaks and considered as long journey makers. Those who answered zonal are short to medium distance commuters. The remaining whose answers are graduate are the one who make irregular home-based others trips such as tourist, shoppers, and visitors.

\subsection{Price Elasticity of Demand by Influencing Factor}

The price elasticity of demand of each level group of influencing factors including age, distance traveled, income, trip purpose, and ticket type is analyzed and clustered by Tukey method as illustrated in Fig. $8-12$.

The key findings from the analysis are summarized as follows:

- The price elasticity of demand is varied by travelers' age. According to the analysis, the teenagers tend to have inelastic demand $(|\mathrm{Ed}|<1.0)$ while the older tend to have higher price elasticity of demand as shown in Fig. 8, implying that the younger has more necessity to travel with a fewer range of travel choices than the older.

- Most travelers are inelastic to price regardless of how far they travel except for some intermediate ranges where travelers may experience intermodal transfers and are exposed to higher travel costs while for long distance trips, travelers tend to have various choices of travel as shown in Fig. 9.

- In line with ages, the low income tend to have less price elasticity of demand than the higher income who have more range of travel choices as shown in Fig. 10.

- Education and work purposes tend to have less price elasticity of demand than shopping or recreational trips, respectively, as shown in Fig. 11.

- Travelers using monthly pass (30 day pass) with some offered discount tend to have less price elasticity of demand than those who use single journey ticket and stored value ticket which are subject to normal transit fare, as shown in Fig. 12.

\subsection{Transit Demand by Fare Strategy}

The ultimate goal of this research is to investigate how the existing transit passengers and non-transit passengers respond to the changes in fare policies in order that the policy makers can implement the most appropriate fare strategies that encourage more transit use but still maintain the satisfactory level of service. The researchers simulate the following hypothetic scenarios and analyses the corresponding effects:

Scenario A: A flat fare policy of 20, 25, 30, and 35 Baht.

Scenario B: A common or rebated fare policy by reducing the total entry fee by 5,10 , and 15 Baht. follows:

The key findings from the analysis are summarized as

Flat fare tend to attract more elder passengers than teenagers who already pay lower transit fares and are mostly inelastic to changes in transit fare levels. On the other hand, the common fare policies seem to favor all ages of transit users equally and 5 Baht reduction per trip is the most appropriate scheme without exceeding the system capacity as shown in Table 3.

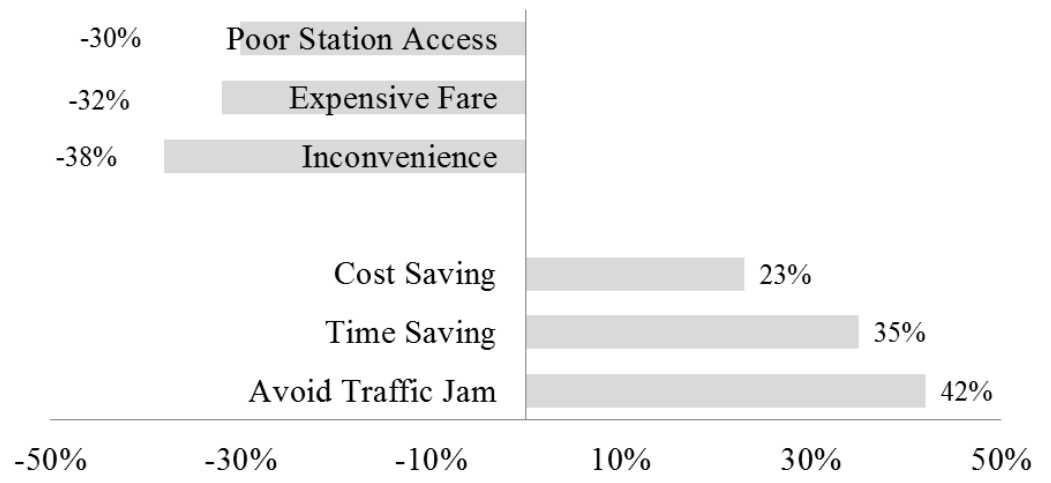

Fig. 6. Attitude toward mass transit use 


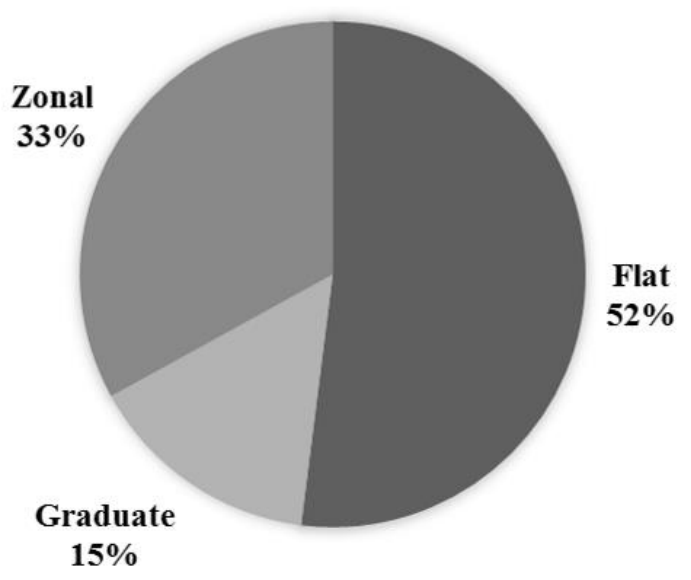

Fig. 7. Attitude toward transit fare structure

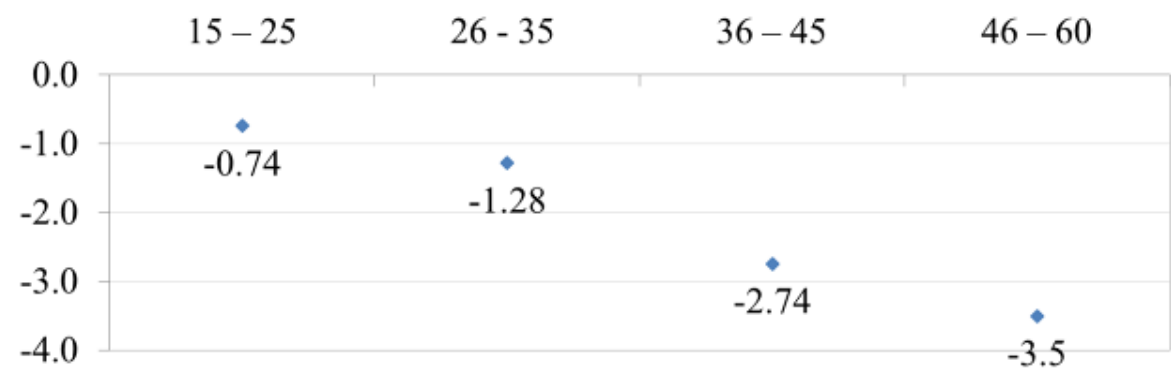

Fig. 8. Price elasticity of demand by age group (years)

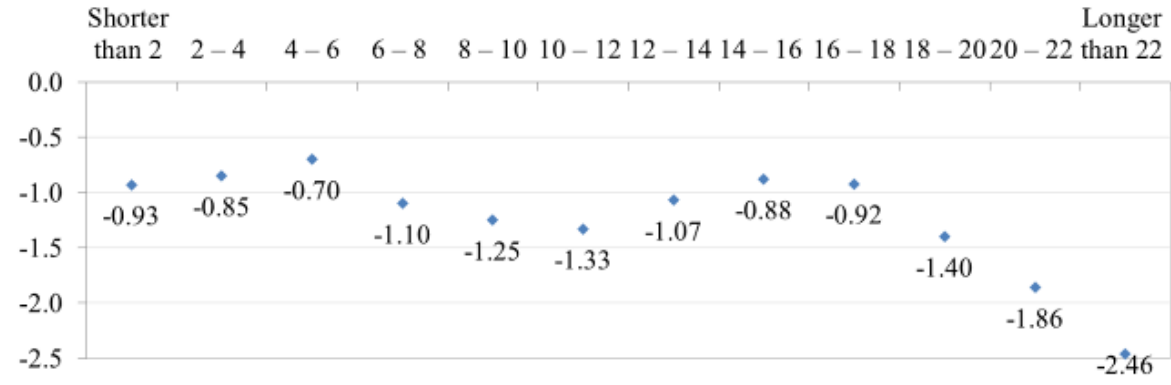

Fig. 9. Price elasticity of demand by distance traveled (kilometers)

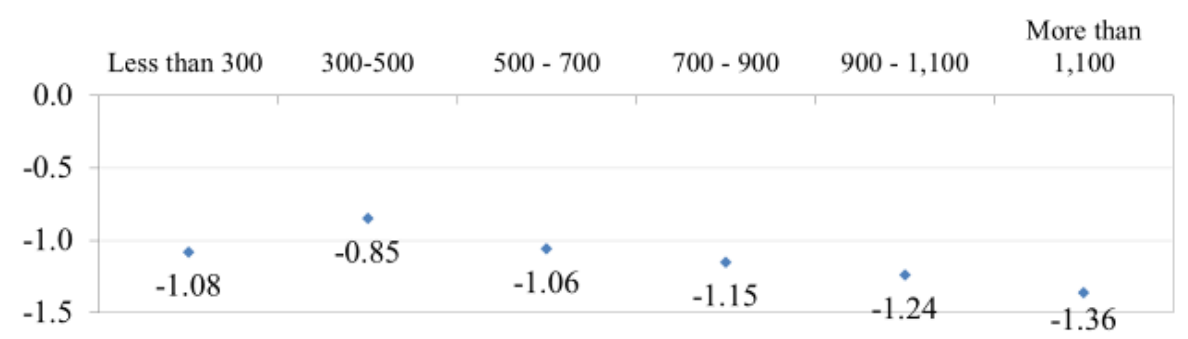

Fig. 10. Price elasticity of demand by income (US dollars per month)

\begin{tabular}{r|ccc|} 
& Home-based Education & Home-based Work & Home-based Others \\
0.0 & & & \\
-0.5 & - & - \\
-1.0 & -0.81 & -1.07 & \\
-1.5 & & & -1.94 \\
-2.0 & & \\
-2.5 & & \\
\hline
\end{tabular}

Fig. 11. Price elasticity of demand by trip purpose 


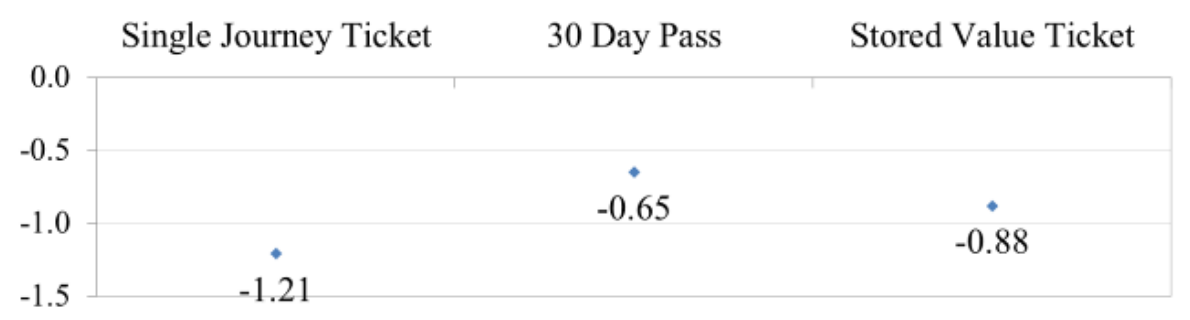

Fig. 12. Price elasticity of demand by ticket type

Despite its simplicity, a disadvantage of flat fare policy is inequity, where short-distance travelers seem to subsidize the system operating cost for long-distance travelers who enjoy the relatively lower fare price. This adverse effect is obviously shown in Table 4. Although the flat fare of 20 Baht as proposed by the government seems to attract more passengers to the system, it significantly attracts the long-distance traveler (18-22 kilometers). In the common fare policy, all transit demand group are equally offered the rebate amount of initial entry fee, so the total transit demand will collectively increase and 10 Baht reduction per trip is the most appropriate scheme without exceeding the system capacity as shown in Table 4.

Sensitivity to changes in transit fares for all income classes is quite similar. This reflects the price elasticity of demand by income as shown in Fig. 9. The result of simulation shows that reduction of the entry fee by only 5 Baht per trip will attract the same passengers as 20 Baht flat fare policy. However, the common fare policy with 10 Baht reduction per trip is the most appropriate scheme without exceeding the system capacity as shown in Table 5.

Similar to age group analysis, flat fare tend to attract more shoppers (home-based other purpose) and workers (home-based work purpose) than students (home-based education purpose) who already pay lower transit fares and are mostly inelastic to changes in transit fare levels. On the other hand, the common fare policies seem to favor all ages of transit users equally and 10 Baht reduction per trip is the most appropriate scheme without exceeding the system capacity as shown in Table 6.

Similar to age group and trip purpose analysis, flat fare tend to attract more single-journey ticket users than 30-day pass and stored value ticket users who are mostly commuters and already get special discount for frequent travelling. The latter group is mostly inelastic to changes in transit fare levels. On the other hand, the common fare policies seem to favor all ages of transit users equally and 10 Baht reduction per trip is the most appropriate scheme without exceeding the system capacity as shown in Table 7.

Whether the reduction in transit fare reduces the total fare revenue depends on price elasticity of demand as shown in Tables 3-7. If the level group is inelastic to price, reduction of fare price will reduce the total fare revenue and vice versa for the elastic demand group. The network capacity is also needed to be taken into consideration. For example, most of transit systems in Bangkok are operated with 4-car train. If the minimum headway is already achieved at present, the only approach to increase the line capacity is to lengthen the train set from 4-car into 6-car train which is equivalent to 50 percent increase in line capacity as in Eq. (8). Therefore, the common fare strategy will be most effective if majority of target groups are elastic to price but with changes in transit demand not exceeding reserve capacity.

Reduction of transit fare by 10 Baht according to the common fare strategy will equally attract more passengers from all level groups of influencing factors including age, distance traveled, income, trip purpose, and ticket type as appear in shaded boxes of Tables 3-7. One may wonder if such decrease in transit fare by 10 Baht will have a negative effect on transit operators' revenue. The answer is no as long as most transit users have an elastic demand. For example, if the number of transit users in Bangkok is currently 700,000 passengers per days, each passenger pay approximately 40 Baht on their transit fares. By implementing common fare policy, each passenger is offered a 10 Baht reduction in transit fare but 35 percent more of passengers are attracted into the system. Therefore the total revenue will change from $700,000 \times 40=28$ million Baht into 945,000 x $30=28.4$ million Baht.

Table 3. Changes in transit demand due to changes in fare policy by age group

\begin{tabular}{cccccccc}
\hline \multirow{2}{*}{$\begin{array}{c}\text { Age } \\
\text { Group } \\
\text { (Years) }\end{array}$} & \multicolumn{3}{c}{ Flat Fare } & \multicolumn{3}{c}{ Common Fare } \\
\cline { 2 - 8 } & 20 & 25 & 30 & 35 & -5 & -10 & -15 \\
\hline $15-25$ & $-7 \%$ & $-27 \%$ & $-48 \%$ & $-69 \%$ & $21 \%$ & $42 \%$ & $62 \%$ \\
$25-35$ & $23 \%$ & $4 \%$ & $-14 \%$ & $-32 \%$ & $18 \%$ & $36 \%$ & $54 \%$ \\
$35-45$ & $68 \%$ & $32 \%$ & $-4 \%$ & $-40 \%$ & $36 \%$ & $72 \%$ & $108 \%$ \\
$45-60$ & $107 \%$ & $46 \%$ & $-16 \%$ & $-77 \%$ & $61 \%$ & $122 \%$ & $183 \%$ \\
\hline
\end{tabular}


Table 4. Changes in transit demand due to changes in fare policy by distance traveled

\begin{tabular}{|c|c|c|c|c|c|c|c|}
\hline \multirow{2}{*}{$\begin{array}{c}\text { Distance } \\
\text { Range } \\
\text { (Kilometers) }\end{array}$} & \multicolumn{4}{|c|}{ Flat Fare } & \multicolumn{3}{|c|}{ Common Fare } \\
\hline & 20 & 25 & 30 & 35 & -5 & -10 & -15 \\
\hline $0-2$ & $-16 \%$ & $-35 \%$ & $-54 \%$ & $-73 \%$ & $19 \%$ & $38 \%$ & $57 \%$ \\
\hline $2-4$ & $5 \%$ & $-14 \%$ & $-33 \%$ & $-52 \%$ & $19 \%$ & $38 \%$ & $57 \%$ \\
\hline 4-6 & $10 \%$ & $-8 \%$ & $-26 \%$ & $-45 \%$ & $18 \%$ & $36 \%$ & $55 \%$ \\
\hline $6-8$ & $39 \%$ & $21 \%$ & $3 \%$ & $-15 \%$ & $18 \%$ & $36 \%$ & $54 \%$ \\
\hline $8-10$ & $49 \%$ & $32 \%$ & $16 \%$ & $-1 \%$ & $16 \%$ & $33 \%$ & $49 \%$ \\
\hline $10-12$ & $40 \%$ & $22 \%$ & $3 \%$ & $-15 \%$ & $18 \%$ & $36 \%$ & $55 \%$ \\
\hline $12-14$ & $52 \%$ & $34 \%$ & $16 \%$ & $-2 \%$ & $18 \%$ & $36 \%$ & $54 \%$ \\
\hline $14-16$ & $28 \%$ & $4 \%$ & $-20 \%$ & $-44 \%$ & $24 \%$ & $48 \%$ & $72 \%$ \\
\hline $16-18$ & $9 \%$ & $-9 \%$ & $-27 \%$ & $-45 \%$ & $18 \%$ & $36 \%$ & $54 \%$ \\
\hline $18-20$ & $117 \%$ & $100 \%$ & $83 \%$ & $67 \%$ & $17 \%$ & $33 \%$ & $50 \%$ \\
\hline $20-22$ & $187 \%$ & $160 \%$ & $133 \%$ & $107 \%$ & $27 \%$ & $53 \%$ & $80 \%$ \\
\hline
\end{tabular}

Table 5. Changes in transit demand due to changes in fare policy by income

\begin{tabular}{|c|c|c|c|c|c|c|c|}
\hline \multirow{2}{*}{$\begin{array}{c}\text { Income } \\
\text { (USD per month) }\end{array}$} & \multicolumn{4}{|c|}{ Flat Fare } & \multicolumn{3}{|c|}{ Common Fare } \\
\hline & 20 & 25 & 30 & 35 & -5 & -10 & -15 \\
\hline Less than 300 & $15 \%$ & $-2 \%$ & $-19 \%$ & $-36 \%$ & $17 \%$ & $34 \%$ & $51 \%$ \\
\hline $300-500$ & $21 \%$ & $1 \%$ & $-19 \%$ & $-39 \%$ & $20 \%$ & $40 \%$ & $61 \%$ \\
\hline $500-700$ & $13 \%$ & $-7 \%$ & $-26 \%$ & $-46 \%$ & $20 \%$ & $39 \%$ & $59 \%$ \\
\hline $700-900$ & $28 \%$ & $11 \%$ & $-6 \%$ & $-23 \%$ & $17 \%$ & $34 \%$ & $51 \%$ \\
\hline $900-1,100$ & $32 \%$ & $16 \%$ & $0 \%$ & $-16 \%$ & $16 \%$ & $31 \%$ & $47 \%$ \\
\hline More than 1,100 & $36 \%$ & $9 \%$ & $-19 \%$ & $-46 \%$ & $27 \%$ & $54 \%$ & $82 \%$ \\
\hline
\end{tabular}

Table 6. Changes in transit demand due to changes in fare policy by trip purpose

\begin{tabular}{ccccccccc}
\hline \multirow{2}{*}{ Objectives } & \multicolumn{4}{c}{ Flat Fare } & \multicolumn{4}{c}{ Common Fare } \\
\cline { 2 - 8 } & 20 & 25 & 30 & 35 & -5 & -10 & -15 \\
\hline Home-based Others & $25 \%$ & $8 \%$ & $-8 \%$ & $-24 \%$ & $16 \%$ & $32 \%$ & $49 \%$ \\
Home-based Work & $25 \%$ & $5 \%$ & $-14 \%$ & $-34 \%$ & $20 \%$ & $39 \%$ & $59 \%$ & $46 \%$ \\
Home-based Education & $-11 \%$ & $-34 \%$ & $-56 \%$ & $-79 \%$ & $23 \%$ & $69 \%$ \\
\hline
\end{tabular}

Table 7. Changes in transit demand due to changes in fare policy by ticket type

\begin{tabular}{cccccccc}
\hline \multirow{2}{*}{ Ticket Type } & \multicolumn{4}{c}{ Flat Fare } & \multicolumn{4}{c}{ Common Fare } \\
\cline { 2 - 8 } & 20 & 25 & 30 & 35 & -5 & -10 & -15 \\
\hline One Trip & $32 \%$ & $14 \%$ & $-4 \%$ & $-22 \%$ & $18 \%$ & $36 \%$ & $54 \%$ \\
30 Days Pass & $8 \%$ & $-7 \%$ & $-23 \%$ & $-38 \%$ & $15 \%$ & $31 \%$ & $46 \%$ \\
Stored Value Ticket & $12 \%$ & $-7 \%$ & $-27 \%$ & $-47 \%$ & $20 \%$ & $39 \%$ & $59 \%$ \\
\hline
\end{tabular}

\section{Conclusions and Recommendations}

The old, long-distance, and high-income passengers have higher price elasticity of demand than the young, short-distance, and low-income passengers. The government policy of 20 Baht flat fare can attract more mass transit patrons and generate more revenue as most passengers are elastic to price. Despite advantage in higher revenue, the 20 Baht flat fare policy will make the system unnecessarily more crowded, discourage short-distance passengers (socially inequitable) and miss higher revenue that the government could earn from longer-distance trips. Therefore, the research outcomes recommend the optimal level of new rebated entry fee 
for common ticketing system that has the same impact on passengers' choice as that of the flat fare policy. The result shows that reduction of the entry fee by only 5 Baht per trip it will attract the same passengers as 20 Baht flat fare policy (as shown in Table 5). From the analysis if transit operators agree to mutually implement common fare policy that reduce the initial entry fare by 10 Baht, the system can still encourage mass transit Patronage, maintain service quality (not too crowded), and sustain government or operators revenue.

The recommendations for future research to compliment the gaps of this research study are as follows:

- Graduate fare, common or rebated fare, and flat fare are the only fare structures investigated in this research study. Other fare structure such as zonal fare should be incorporated in the future research.

- Other influencing factors such as time-of-the-day and number of transfers are not incorporated in this research study and should be taken into consideration in the future research.

- Cost-benefit of analysis of each fare policy should be taken into account as in Tao et al. (2011).

\section{Acknowledgements}

The authors would like to express grateful thanks to Bangkok Mass Transit System Public Company Limited (BTSC) and the Office of Transport and Traffic Policy and Planning (OTP) for their courtesy in allowing the authors to publish some of their materials in this article. Sincere thanks are also extended to every member of research assistant team in Civil Engineering Department at Kasetsart University especially Mr. Jakkrit Orachunsuntorn, Mr. Natchanon Sangkaew, and Mr. Jetsada Udomthumruks who devote their time and effort on data collection and detailed analysis in the pilot study. Their hard work is highly appreciated.

\section{References}

Litman, T. (2004). Transit price elasticities and crosselasticities, Journal of Public Transportation, 7(2), 37-58.

Litman, T. (2012). Understanding transport demands and elasticities: How prices and other factors affect travel behavior. Technical Report, Victoria Transport Policy Institute.

Marshall, A. (1920). Principles of Economics (Revised edition ed.), Macmillan, London; reprinted by Prometheus Books.

McCollom, B.E. and Pratt, R. (2004). Traveler response to transportation system changes: Chapter 12 Transit pricing and fares. TCRP Report 95, Transit Cooperative Research Program, the Federal Transit Administration, Transportation Research Board.

Orachunsuntorn, J., Sangkaew, N., Udomthumruks, J. and Sirikijpanichkul, A. (2013). A study on influence of common ticketing on modal choice decision: A case study of Bangkok mass transit user's behavior. Civil Engineering Project: Academic Paper, Kasetsart University.

Parkin, M., Powell, M., Matthews, K. (2002). Economics. Addison-Wesley, Harlow.
Paulley, N., Balcombe, R., Mackett, R., Titheridge, H., Preston, J., Wardman, M., Shires, J. and White, P. (2006). The demand for public transport: The effects of fares, quality of service, income and car ownership, Transport Policy, 13(4), 295-306.

Tao, R., Liu, S., Huang, C., and Tam, C. M. (2011). Cost-benefit analysis of high-speed rail link between Hong Kong and Mainland China, Journal of Engineering, Project, and Production Management, 1(1), 36-45.

Taylor, B.D., Miller, D., Iseki, H. and Fink, C. (2009). Nature and/or nurture? Analyzing the determinants of transit ridership across US urbanized areas, Transportation Research A, 43, 60-77.

TRL (2004). The demand for public transit: A practical guide, Report TRL 593, Transportation Research Laboratory.

Vukan, R. V. (2005). Urban Transit Operations, Planning and Economics, John Wiley \& Sons.

Wang, J. (2011). Appraisal of factors influencing public transport patronage, Research Report 434, NZ Transport Agency.

Wardman, M. and Shires, J. (2003). Review of fares elasticities in Great Britain, Working Paper 573, Institute of Transport Studies, University of Leeds.

Wardman, M. and Shires, J. (2011). Price elasticities of travel demand in Great Britain: A meta-analysis, Transportation Research Board Annual Meeting, Paper 11-3544.

Wu, C., Jeff, F. and Hamada, M. (2000). Experiments: Planning, Analysis, and Parameter Design Optimization, 1st Ed., Wiley-Interscience, USA.

Yamane, T. (1967). Statistics: An Introductory Analysis, $2^{\text {nd }}$ Ed, Harper and Row, New York.

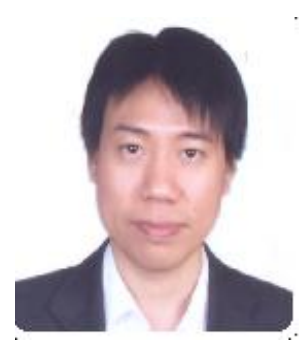

Dr. Ackchai Sirikijpanichkul is a full-time lecturer at Department of Civil Engineering, Faculty of Engineering, Kasetsart University, with memberships of Transport Planning Society (TPS), United Kingdom in 2008, Thai Society for Transportation and Traffic Studies (TSTS) in 2000 and Registered Professional Engineer, Engineering Institute of Thailand (EIT) since 1998. He is also working as a program coordinator of Kasertsart University Rail Engineering Research Group (KU-Rail). His research interests include Urban Mass Transportation Planning, Freight and Logistics, Transportation Demand Modeling, Decision Support Systems, Green Transport and Incident/ Disaster Management.

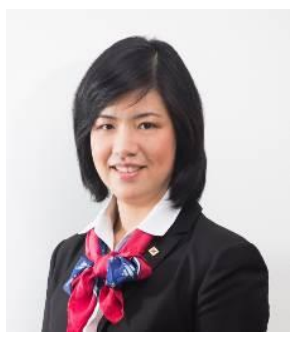

Dr. Sarintorn Winyoopadit is Public Sector Development Officer, Office of the Public Sector Development Commission Thailand (OPDC), with memberships of Transport Planning Society (TPS), United Kingdom in 2008, Thai Society for Transportation and Traffic 
Studies (TSTS) in 2001 and Registered Professional Engineer, Engineering Institute of Thailand (EIT) since 1999. She is also an advisor to Kasertsart University Rail Engineering Research Group (KU-Rail). Her research interests include Traffic Management, Intelligent Transport System, Transportation Demand Modeling, Traffic Safety Study and Rail Transit Planning. 